\title{
O “DIREITO À DESINDEXAÇÃO”: REPERCUSSÕES DO CASO GONZÁLEZ VS GOOGLE ESPANHA
}

\section{THE "RIGHT OF DEINDEXATION": REPERCUSSIONS OF THE GONZÁLEZ VS GOOGLE SPAIN CASE}

\author{
Pedro Henrique Machado da Luz ${ }^{1}$
} Marcos Wachowicz ${ }^{2}$

\begin{abstract}
Resumo: O objetivo com este estudo foi investigar a decisão proferida no ano 2014, pelo Tribunal de Justiça da União Europeia, no que ficou conhecido como o caso González vs Google Espanha. Para tanto, fez-se uma análise sistematizada dos principais aspectos do caso, consistindo em uma introdução ao conflito entre as partes, alguns fatos relevantes, a história processual da lide, as questões jurídicas presentes somadas aos precedentes utilizados pela Corte decisória, a decisão adotada pelo Tribunal de Justiça da União Europeia, informações complementares sobretudo acerca do impacto desse caso e, finalmente, considerações críticas e inquietações sobre o surgimento do chamado direito à desindexação e sua potencial recepção no cenário brasileiro. Escolheu-se tal julgado como fonte de estudo. pois ele bem representa a tensão entre as novas tecnologias próprias da sociedade informacional e o direito, em sua missão de proteção de direitos fundamentais, especialmente, para o caso, os direitos de personalidade, na modalidade de resguardo aos dados pessoais.
\end{abstract}

Palavras-chave: Direito à desindexação. González vs Google Espanha. Motores de busca. Direitos fundamentais. Proteção de dados pessoais.

\begin{abstract}
The purpose of this case study is to investigate the decision handed down in the year 2014 by the Court of Justice of the European Union in what is known as the González vs. Google Spain case. To this end, a systematic analysis of the main aspects of the case was made, consisting of an introduction to the conflict between the parties, some relevant facts, the procedural history of the case, the legal issues present in addition to the precedents used by the decision court, the decision adopted by the Court of Justice of the European Union, additional information mainly on the impact of this case and finally, critical considerations and concerns about the emergence of the so-called right to de-indexation and its potential reception in the Brazilian scenario. Such case was chosen as a source of study because it represents the tension between the new technologies of the information society and the law, in its mission to protect fundamental rights, especially for the case, the rights of personality, in the modality of protection of personal data.
\end{abstract}

Keywords: Deindexation. González vs Google Spain. Search engines. Fundamental rights. Personal data protection.

\footnotetext{
1 Especialista em Direito Constitucional pela Academia Brasileira de Direito Constitucional; mestrando em Direito do Estado pela Universidade Federal do Paraná; Rua XV de novembro, 1299, Centro, 80060-000, Curitiba, Paraná, Brasil; pedrohmluz@gmail.com; http://orcig.org/0000-0003-1112-6226

2 Doutor em Direito pela Universidade Federal do Paraná; Mestre em Direito pela Universidade Clássica de Lisboa, Portugal; Professor de Direito no Curso de Graduação da Universidade Federal do Paraná; marcos.wachowicz@gmail.com; http:// orcig.org/0000-0003-1381-9077
} 


\section{Introdução}

foco do presente estudo centra-se em um caso que chegou às portas do Tribunal de Justiça da União Europeia e envolveu, de um lado, os direitos da personalidade de um cidadão espanhol e, de outro, as pretensões econômicas de uma das maiores empresas do mundo, o Google. Em 1998, o jornal espanhol La Vanguardia publicou duas notícias acerca de um leilão público a fim de dar conhecimento sobre a venda de um imóvel de propriedade do advogado Mario Costeja González, por ocasião de um débito contraído com a seguridade social da Espanha. Tal venda nunca chegou a se concretizar, pois González quitou a dívida a tempo.

Contudo, anos depois, ao pesquisar seu nome no provedor de busca Google, Costeja González verificou que ainda constava a antiga e defasada notícia do La Vanguardia o veiculando ao débito já extinto. Ao saber disso e após ter negado seu pedido de remoção das notícias pelo La Vanguardia em 2009, Mario Costeja decidiu ingressar, em 2010, com um processo administrativo perante a Agência Espanhola de Proteção de Dados (AEPD), subindo ao Tribunal de Justiça da União Europeia em 2014. O julgado ficou conhecido como González vs Google Espanha e teve como principal efeito o advento de um "direito à desindexação" de dados de pesquisa, relacionado com o direito fundamental à privacidade. O caso também serviu para que fossem assentados os limites da Diretiva 95/46/CE, que trata da proteção dos dados pessoais na União Europeia. ${ }^{3}$

Tratou-se, neste estudo interdisciplinar, de apresentar um relatório do caso sobredito e construir uma crítica norteada por contribuições por diferentes ramos do saber. Assim, foi possível observar os impactos dessa decisão e as principais questões pendentes sobre o tema em sede nacional, visto que o Poder Judiciário já enfrenta e enfrentará cada vez mais casos desafiadores relacionados à proteção dos direitos da personalidade na internet.

\section{Fatos do caso González vs Google Espanha}

O caso González vs Google Espanha, julgado em 2014 pelo Tribunal de Justiça da União Europeia, foi um marco no que toca ao tema da proteção da personalidade. Isso, pois trouxe ao centro da dogmática jurídica uma nova ferramenta útil à tutela desse direito fundamental, qual seja a desindexação ${ }^{4}$ dos dados agrupados por motores de busca, apresentando-se ainda como uma alternativa à difícil e lesiva remoção de dados.

Foi também um relevante exemplo dos novos desafios trazidos pelo que Castells (1999, p. 57) cunhou como "sociedade informacional", em que a informação passa a ocupar um local de

\footnotetext{
3 Tal diretiva atualmente encontra-se revogada pelo novo Regulamento Geral sobre a Proteção de Dados (GDPR), aprovado em 15 de abril de 2016 e entrada em vigor na data de 25 de maio de 2018 (EUROPA, 2016).

4 A ciência da computação, como ramo autônomo do saber, pouco utiliza o termo "desindexação» no Brasil, pois prefere recorrer à expressão «indexação de dados» ou somente «indexação», cujos pilares são os metadados, os buscadores, os usuários e o posicionamento web. Para um estudo mais aprofundado, consultar Gil-Leiva (2007).
} 
primazia nos modelos empresariais por conta de seu alto valor econômico. Percebe-se que o Google, integrante do polo passivo do julgado, é precisamente um dos maiores exemplos de uma empresa que utiliza a indexação de informações para exibir resultados de busca e, por meio de resultados pagos, ${ }^{5}$ auferir rendimentos.

O impacto desse caso foi tão grande que, após essa decisão, o Google possibilitou a desindexação em grande escala na Europa ao abrir um formulário permitindo a supressão de determinados resultados de busca ${ }^{6}$ após uma análise fática extrajudicial. Com isso, a empresa recebeu cerca de 700.000) pedidos desde a decisão paradigmática de 2014, divulgando um relatório chamado Transparency Report, que será melhor explorado na parte final do estudo.

\section{História processual}

Na data de 05 de março de 2010, Costeja González, cidadão espanhol, ingressou com uma reclamação judicial contra o La Vanguardia Ediciones SL, jornal de grande circulação na região da Catalunha; na mesma ação, também acionou judicialmente o Google Spain e o Google Inc. A ação originou-se do fato de que, ao buscar-se o nome completo do Sr. González na ferramenta de pesquisa do Google, os resultados traziam duas páginas do referido jornal La Vanguardia, datadas de 19 de janeiro e 09 de março de 1998, em que o nome de González estava relacionado com procedimentos de execução fiscal de débitos de seguridade social (EUROPA, 2014).

Em sua argumentação, o reclamante apontou que tal dívida já havia sido quitada. O pedido da inicial centrou-se, portanto, em duas frentes: na remoção ou alteração dessas páginas, pelo jornal La Vanguardia, a fim de que os dados pessoais relacionados ao nome do autor não mais aparecessem nas buscas, e na remoção ou omissão dos dados de busca envolvendo seu nome nos mecanismos de busca Google Spain e Google Inc.

No âmbito administrativo, em 30 de julho de 2010, a Agência Espanhola de Proteção de Dados rejeitou o primeiro pleito, esclarecendo que, no tocante ao pedido dirigido ao La Vanguardia, (a) a publicação estava juridicamente justificada, pois ocorreu após ordem do Ministro do Trabalho e Justiça Social, ou seja, surgiu como decorrência de uma política pública que intentava dar maior publicidade aos débitos sociais. Todavia, atinente ao pedido, (b) a referida agência sustentou que motores de busca como o Google estão sujeitos aos ditames das leis de proteção de dados, eis que são responsáveis pelo processamento de dados e atuam como intermediários da informação.

\footnotetext{
5 "A história provou que o Google AdWords é a maior revolução propagandística dos últimos 50 anos. Nunca antes foi possível, com apenas 5 dólares, abrir uma conta e ter novos alvos, precisamente direcionados para vir ao seu website em questão de minutos." (MARSHALL; RHODES; TODD, 2014, p. 34, tradução nossa).

6 O link do formulário de remoção de conteúdo do Google é bastante amplo e contempla diferentes hipóteses, como a) dados pessoais sensíveis; b) retificação de dados em resultados de pesquisa Google; c) associação de dados pessoais ou de empresas com conteúdo adulto; d) identificação de conteúdo difamatório em resultados de pesquisa Google (GOOGLE, 2018a).
} 
Em seu argumento fulcral, o órgão administrativo externou a visão de que poderia requerer a retirada de dados e a proibição de acesso a determinados dados por motores de busca quando a localização e disseminação de tais dados atentasse contra o direito fundamental de proteção de dados e a dignidade da pessoa lato sensu. $\bigcirc$ mecanismo para atingir esse fim não seria necessariamente a remoção dos dados, mas a desindexação das buscas.

Irresignados com a decisão, o Google Spain e a Google Inc. ajuizaram recursos na Audiência Nacional, um órgão judiciário espanhol com competência sobre todo o território do país. ${ }^{7}$ Em sua argumentação defensiva, apontaram que o Google não fazia tratamento de dados nas aplicações de internet ${ }^{8}$ em relação a terceiros. E, mesmo que tratasse diretamente desses dados, a reclamada não poderia ser responsabilizada pelo seu teor, pois não teria conhecimento nem controle sobre eles. Por entender que a matéria de fundo do julgamento envolvia a interpretação da Diretiva 95/46/CE, ${ }^{9}$ a Audiência Nacional declinou de sua competência e remeteu o processo ao Tribunal de Justiça da União Europeia, órgão judiciário de cúpula no contexto da União Europeia. ${ }^{10}$

\section{Questões jurídicas e os precedentes utilizados pelo Tribunal de Justiça da União Europeia}

Estava em disputa, no contexto do caso González vs Google Espanha, o direito fundamental à proteção de dados pessoais, decorrente da privacidade (reconhecido pela Diretiva 95/46/CE), e a possibilidade de remoção ou desindexação do conteúdo supostamente lesivo, ora por parte do jornal La Vanguardia, no tocante à remoção, ora por parte do Google Espanha e do Google Inc., acerca da desindexação. Contudo, a matéria de fundo que ocasionou que o caso chegasse ao Tribunal de Justiça da União Europeia foram justamente os limites da aplicação da Diretiva 95/46/CE.

Para solucionar o impasse, a Corte utilizou um precedente para fixar sua posição, qual fosse o caso Bodil Lindqvist vs Åklagarkammaren i Jönköping (Case C-101/01), de 2003, em que uma trabalhadora de uma igreja na Suécia decidiu publicar uma revista sobre sua paróquia local contendo informações de outros trabalhadores, como seus nomes, hobbies e números de telefone, colocando-as na internet sem o consentimento destes. Nessa ocasião, o Tribunal de Justiça da União Europeia decidiu que a

\footnotetext{
Seria o equivalente ao Superior Tribunal de Justiça no Brasil (RODRIGUES JÚNIOR, 2014).

8 Uma definição de aplicações de internet pode ser encontrada no artigo 5, VII, do Marco Civil da Internet: "aplicações de internet: o conjunto de funcionalidades que podem ser acessadas por meio de um terminal conectado à internet." (BRASIL, 2014).

9 Tal diretiva, datada de 24 de outubro de 1995, tem aplicação sobre todos os países da União Europeia e refere-se à proteção de pessoas naturais no que diz respeito ao tratamento de dados pessoais e à livre circulação desses dados. Interessante notar, portanto, que os países integrantes da União Europeia têm regramento próprio sobre o tema desde 1995, enquanto o Brasil ainda não editou uma lei específica acerca da proteção de dados pessoais. Ademais, a Espanha, como já citado, tem na estrutura de sua administração pública uma autarquia, a Agência Espanhola de Proteção de Dados, incumbida dessa matéria (UNIÃO EUROPEIA, 1995).

10 A partir de então, alguns estudiosos do caso passaram a nominá-lo González e AEPD vs. Google Espanha, pelo fato de que o órgão administrativo europeu havia respaldado uma das pretensões do autor, qual seja a de considerar a empresa ré como gestora de dados, atribuindo-lhe responsabilidade diferenciada. Utilizaremos, nesse estudo, a nominação González vs Google Espanha.
} 
publicação de informações pessoais em sites da internet constitui "processamento de informações", nos exatos termos do art. $2^{\circ}$ da Diretiva 95/46/CE, atraindo, portanto, a aplicação da diretiva, mesmo que a atividade da senhora Lindqvist não visasse propriamentea o lucro (EUROPA, 2003).

Outro precedente citado, que também tratou dos limites de aplicação da referida diretiva, foi do caso Satakunnan Markkinapörssi and Satamedia vs Finland (Case C-73/07), em que duas empresas privadas finlandesas publicaram a renda anual tributável e os ativos de cidadãos finlandeses, por meio impresso e por mensagens de celular (SMS). Diante disso, o Gabinete de Proteção de Dados finlandês, autoridade vinculada ao Ministério da Justiça da Finlândia, decidiu ingressar judicialmente contra as empresas, sob o argumento de que tais ações extrapolariam seu direito de liberdade de imprensa. Após um trâmite processual longo, o Tribunal de Justiça da União Europeia decidiu que, ao se fazer um cotejo entre o direito de liberdade de expressão ou de imprensa das empresas e o direito à privacidade dos retratados, a publicação de informações pessoais não poderia ser enquadrada como parte da atividade jornalística, aplicando-se, ainda, por conta da publicação desses dados, a Diretiva 95/46/CE, nos termos do artigo $2^{\circ}$, pelo fato de que as empresas realizaram processamento de dados pessoais (EUROPA, 2009).

Os precedentes utilizados pela Corte revelam, portanto, o amplo escopo de aplicação da Diretiva 95/46/CE. No caso investigado neste estudo, estava a se discutir se o Google realiza processamento de dados pessoais nos termos da Diretiva 95/46/CE, o que, caso confirmado, atrairia a competência do Tribunal de Justiça da União Europeia para decidir o caso González vs Google Espanha.

\section{A decisão}

A ação foi finalmente julgada pelo Tribunal de Justiça da União Europeia em 13 de maio de 2014. Os objetos de análise foram especificamente os artigos $2^{\circ}$, alíneas "b" e "d", também o artigo 4", inciso 1, alíneas "a" e "c", o artigo 12, alínea "b", e finalmente o artigo 14, \$1, alínea "a", todos da já citada Diretiva 95/46/CE, bem como do artigo $8^{\circ}$ da Carta de Direitos Fundamentais da União Europeia. A principal discussão, portanto, seria se motores de busca como o Google realizam processamento de dados e, caso assim considerado, se haveria responsabilidade por parte da empresa nesse trato, mediante exegese da referida diretiva.

Nesse ponto, o órgão decisório consignou:

Therefore, it must be found that, in exploring the internet automatically, constantly and systematically in search of the information which is published there, the operator of a search engine 'collects' such data which it subsequently 'retrieves', 'records' and 'organises' within the framework of its indexing programmes, 'stores' on its servers and, as the case may be, 'discloses' and 'makes available' to its users in the form of lists of search results. As those operations are referred to expressly and unconditionally in Article 2(b) of Directive 95/46/CE, they must be classified as 'processing' within the meaning of that provision, regardless of the fact that the operator of the search engine also carries out the 
same operations in respect of other types of information and does not distinguish between the latter and the personal data. ${ }^{11}$

Desse modo, o primeiro ponto assentado na decisão foi de que o Google realiza efetivamente o processamento de dados, nos moldes do texto previsto no artigo $2^{\circ}$ da Diretiva 95/46/CE, com expressa menção dos já citados casos Bodil Lindqvist vs Åklagarkammaren i Jönköping e Satakunnan Markkinapörssi and Satamedia vs Finland.

No atinente à responsabilidade do Google por decorrência desse processamento, o Tribunal de Justiça da União Europeia asseverou, no ponto 33 das questões prejudiciais, que:

It is the search engine operator which determines the purposes and means of that activity and thus of the processing of personal data that it itself carries out within the framework of that activity and which must, consequently, be regarded as the 'controller' in respect of that processing pursuant to Article 2(d)..$^{12}$ (EUROPA, 2014).

Não obstante, pelo fato de que as atividades dos motores de busca podem afetar sobremaneira direitos fundamentais, mormente a privacidade e a proteção de dados pessoais, aquele que opera o provedor de busca deve assegurar que sua atividade esteja em acordo com o disposto na Diretiva 95/46/CE. Consequentemente, concluiu o tribunal que haveria responsabilidade do motor de busca na formatação de dados pessoais pela possibilidade latente de que sua atividade viesse a afetar direitos fundamentais. ${ }^{13}$

Superadas tais questões, tratou a Corte de investigar o reconhecimento ou não da existência de um direito à desindexação ou exclusão de referências ou links nos mecanismos de busca (SARLET, 2015). Estava-se a julgar se a conduta de indexação dos resultados de busca envolvendo o nome de González seria ilícita, ou seria apenas a divulgação da notícia do La Vanguardia que mereceria reprimenda.

O argumento encontrado pelo Tribunal de Justiça da União Europeia foi de que, ao explorar economicamente a informação ${ }^{14}$ por intermédio de listas de resultados, haveria uma especificidade na atuação do Google em comparação com o La Vanguardia, cabendo àquele a responsabilidade de

\footnotetext{
11 "Assim, deve ser considerado que, por explorar a internet de forma automática, constante e sistemática em busca da informação que é publicada lá, o operador de um mecanismo de busca 'coleta' tal data que é subsequentemente 'recuperada', 'registrada' e organizada na estrutura de seus programas de indexação, também 'guardada' em seus servidores e, dependendo do caso, 'divulgada' e 'disponibilizada' para seus usuários na forma de listas com resultados de pesquisa. De modo que tais operações constam expressamente e incondicionalmente no artigo $2^{\circ}$, alínea b, da Diretiva 95/46/CE, elas devem ser classificadas como 'tratamento' no sentido daquela provisão, independente do fato de que o operador dos mecanismos de busca também realiza essas mesmas operações no tocante a outros tipos de informação e não realiza a distinção entre o último e os dados pessoais." (tradução nossa).

12 "[...] é o operador do motor de busca que determina as finalidades e os meios dessa atividade e, deste modo, do tratamento de dados pessoais que ele próprio efetua no contexto dessa atividade e que deve, consequentemente, ser considerado 'responsável' por esse tratamento por força do referido artigo 2. , alínea d)." (tradução nossa).

13 Esse é um caso interessante para se estudar a eficácia horizontal dos direitos fundamentais no âmbito europeu, apesar de esse não ser o foco do presente trabalho, pois a relação alvo da disputa ocorreu entre agentes privados, tanto na relação entre o La Vanguardia, com Mario González, quanto com o Google e González.

14 Novamente, rememora-se que a informação ocupa papel central na sociedade informacional, por ser o principal commoditie ou a principal matéria-prima produtiva. Ademais, por constituir-se como a base material dessa nova sociedade, o modelo negocial de diversas empresas como o Facebook e o Google baseiam-se na coleta e sistematização de dados (CASTELLS, 1999).
} 
agir de forma a tutelar a proteção dos dados pessoais do requerente, devendo, portanto, desindexar resultados relacionando seu nome ao débito já exinto. ${ }^{15}$

Foi levantando também o argumento de que a desindexação das buscas figura como ação muito menos restritiva do que a remoção de determinada página da internet. De forma corajosa, mas não menos criticável, o órgão decisório determinou ao Google a desindexação dos resultados de busca relacionando o nome de González ao débito já saldado.

\section{Informações complementares}

A decisão proferida pelo Tribunal de Justiça da União Europeia no âmbito do caso González vs Google Espanha suscitou posições majoritariamente favoráveis. Para Sarlet (2015):

Que a decisão do TJUE está destinada a provocar não apenas reações críticas, mas também aplausos (como, aliás, já vem ocorrendo), resulta evidente. Independentemente de se emitir aqui um juízo positivo ou negativo, chama a atenção que os motores de busca como o Google não são um nicho imune a controle e sobre o qual não recai nenhuma responsabilidade, como se de meros intermediários se tratasse, e nisso nos parece, salvo melhor juízo, que o TJUE acertou, o que está inclusive determinando ajustes não apenas na esfera das diretivas da União Europeia como também nas legislações internas dos Estados que a integram.

Já Branco (2015), ao comentar sobre o julgado, ponderou que: "há vários problemas surgindo da implementação do direito ao esquecimento na Internet." Em seguida, colocou diversas questões inquietadoras sobre o tema, como, por exemplo: "quem deveria decidir se o direito ao esquecimento é aplicável? Entidades privadas, como o Google, ou apenas tribunais?" (BRANCO, 2016).

O mais interessante, contudo, antes de serem feitas as considerações sobre tais visões, é observar os impactos que o julgado teve para situações futuras de lesão a direitos da personalidade na internet. Segundo o relatório Transparency Report (GOOGLE, 2018b) publicado pelo próprio Google, desde 29 de maio de 2014, quando foi aberta a possibilidade de desindexação de resultados por intermédio do preenchimento de um formulário, foram feitos mais de 700.000 pedidos à empresa. ${ }^{16}$ Desse enorme montante, $56 \%$ foram efetivamente concedidos, o que representa uma economia processual bastante relevante. Do número total de solicitantes, 88,6\% eram pessoas não públicas. Dentre os sites com maior número de pedidos de desindexação de resultados de busca, constam o Facebook (46.018 solicitações), o Twitter (25.724 solicitações), o Google Plus (33.098 solicitações) e o Youtube (26.516 solicitações).

\footnotetext{
${ }_{15}$ Assim, o site de buscas seria responsável, após pedido do autor, por desindexar os resultados contestados. Esse é um ponto importante, pois seria bastante temerário exigir que o Google desindexasse tais informações de ofício, pois essa conduta poderia gerar verdadeira censura.

16 Ressalta-se que o relatório apenas contempla os pedidos realizados por cidadãos de países integrantes da União Europeia.
} 


\section{Análise crítica do julgado}

A decisão proferida no caso González é de importância monumental para as futuras discussões acerca dos temas direito ao esquecimento, direitos da personalidade na internet e responsabilidade dos provedores de busca. A argumentação despendida pelo órgão decisório tentou e efetivamente conseguiu equilibrar diversos valores importantes pertencentes ao patrimônio jurídico tanto da parte autora quanto da ré. Para tanto, fundamentou a decisão de modo compatível com o que se espera de uma Corte de cúpula.

Assim, a desindexação apresenta-se como um engenhoso e promissor mecanismo de proteção à personalidade na internet, sendo inclusive meio menos restritivo em comparação com, por exemplo, a remoção de uma página, pois, ao simplesmente desindexar, não ocorrerá a supressão material do dado, mas apenas será colocada uma barreira artificial ao seu acesso. Tomando uma analogia bastante elucidativa, seria o mesmo que colocar um livro no fundo de uma prateleira de uma biblioteca; a obra continuaria ali, para todos que quisessem acessá-la, mas haveria uma dificuldade maior em sua busca.

É de se criticar, contudo, a ligeira e acrítica aproximação entre a decisão proferida no caso González vs Google e a polêmica figura do direito ao esquecimento, como se o objeto central da sentença proferida pelo aludido Tribunal fosse estritamente ligado a uma pretensão de esquecimento do autor. A máxima não procede porquanto a decisão foco de estudo citou o right to be forgottten apenas três vezes, de modo en passant, representando um apêndice e não o coração do acórdão. Ademais, o direito ao esquecimento, se entendido em sua acepção clássica, não teria surgido na internet, mas teve expressa menção e reconhecimento nos anos 1960, em um contexto televisivo no famoso caso Lebach, na Alemanha (BRANCO, 2016).

Ainda, deve-se colocar que falar de uma pretensão de esquecimento na internet, completa e sem repercussões, é tarefa impossível; o que pode ser feito, a depender de forte ônus argumentativo e ponderação com demais princípios colidentes no caso concreto, é a desindexação de determinada informação atentatória a um dos direitos de personalidade, contanto que haja possibilidade concreta para tanto, como no caso González vs Google Espanha.

A própria terminologia e alcance do direito ao esquecimento é problemática e há forte divergência na doutrina sobre sua natureza jurídica; seria tal direito uma decorrência do direito à privacidade? Ou, de outra forma, seria um direito relacionado à proteção de dados? Para Parentoni (2015, p. 547-548):

A terceira crítica às nomenclaturas é aquela que, de fato, mais se justifica. Ela propõe tratar, de um lado, right to forget ou right to be forgotten; e, de outro right to oblivion. Os dois primeiros designariam qualquer remoção de conteúdo que de alguma forma afronte a privacidade, independentemente do meio em que ele tenha sido publicado (reportagem impressa, outdoor em via pública, fachadas comerciais, internet, etc). Por sua vez, right to oblivion seria uma subespécie do direito anterior, cujo objeto restringirse-ia, exclusivamente, ao tratamento informatizado de dados pessoais. Ou seja, o right 
to oblivion seria a modalidade contemporânea desse direito, surgida em virtude do desenvolvimento tecnológico, estando contido na modalidade clássica, existente há mais de um século e conhecida como right to forget, right to be forgotten ou right to be let alone.

Também é de se ter bastante cuidado na importação automática da desindexação para o cenário jurídico brasileiro, pelos seguintes motivos: a) não há ainda uma lei específica de proteção de dados pessoais como ocorre no contexto europeu, portanto qualquer decisão nesse sentido seria, do ponto de vista hermenêutico, ativista, ou seja, caberia aos julgadores decidirem sobre o tema a par de qualquer regulação legislativa, incorrendo em um acentuado déficit democrático; b) existe uma prática autoritária de desindexação de dados que detêm interesse público ou constituem a história dos povos, portanto qualquer aplicação desse novel instituto obriga necessariamente uma análise aprofundada e que se utilize da melhor técnica da proporcionalidade e da ponderação de princípios.

Tratando mais detidamente do ponto "a)", entende-se que o Marco Civil da Internet (Lei n. $12.956 / 14)^{17}$ é uma legislação insuficiente para tratar de questões complexas como o direito à desindexação, visto que, no tocante ao tratamento de dados pessoais, a legislação é bastante vaga e, por conseguinte, insuficiente. Apesar de a proteção de dados constar nitidamente como um princípio, alocado no artigo $3^{\circ}$, inexiste qualquer disciplina sobre a responsabilidade dos mecanismos de busca, nem sobre como eles deveriam proceder para efetuarem a desindexação de dados de pesquisa. ${ }^{18}$

Infelizmente, o Brasil é um dos poucos países ainda carentes de uma legislação específica sobre proteção de dados pessoais (MORGADO, 2009), o que prejudica a discussão de certos temas, como, por exemplo, a corriqueira e odiosa prática de mercantilização de dados pessoais pelas empresas, violadora de diversos princípios constitucionais. Tudo pra dizer, então, que em matéria de proteção de dados pessoais a discussão e regulação do tema ainda engatinham em solo pátrio, na contramão do que muitos países - principalmente europeus - vêm fazendo.

Outra inquietação se apresenta na seguinte questão: mesmo que por ventura exista uma regulação legal bastante específica e protetiva em matéria de proteção de dados pessoais, sanando, portanto, o problema trazido anteriormente, a seguinte dúvida permanece: o direito consegue ou conseguiria tutelar a personalidade do cidadão no contexto da internet, em que milhões de páginas são criadas e acessadas a cada minuto? Ou, apesar da proteção, o direito sempre "chegaria atrasado"?

Como seria possível desindexar milhões de páginas agrupadas em diferentes mecanismos de busca? Afinal, embora no caso González vs Google Espanha a ordem tenha sido dirigida ao Google, existem diversos outros sites que prestam serviços de busca parecidos. Ademais, a própria desindexação pode apresentar outros problemas; no caso do Google, ela deveria ser feita apenas para o endereço virtual local do Google - "google.com.br" - ou também para o domínio global - "google.com"?

\footnotetext{
17 Conforme já apontado anteriormente: "O fato é que a Lei do Marco Civil da Internet vem preencher uma lacuna no ordenamento jurídico brasileiro, vez que inexistia qualquer norma dispusesse sobre os princípios, direitos e deveres dos usuários na Internet." (WACHOWICZ, 2015, p. 236).

18 Acreditamos que necessariamente deveria haver uma ordem judicial, sob risco de a desindexação ex officio tornar-se censura por parte dos mecanismos de busca.
} 
Apesar da dúvida parecer, inicialmente, meramente lateral, ela implica em diferentes resultados práticos. Ao adotar-se apenas uma exclusão no domínio local, o resultado da busca ainda apareceria para usuários de outros países ou, ainda, para nacionais que utilizassem programas que mascaram a identidade na internet, chamados de VPN. ${ }^{19}$

Em síntese, de nada adiantaria uma decisão ordenando a desindexação de determinado conteúdo violador dos direitos da personalidade se a execução da decisão não fosse factível ou se seus efeitos não pudessem ser determináveis. O revés apontado, por tocar nas próprias bases do direito e seu papel de regulador social, no contexto de um ambiente dinâmico como a internet, é um dos, senão o maior, obstáculo a ser superado no tema.

\section{Referências}

BRANCO, Sergio. Nove perguntas sobre o "Direito ao esquecimento". ITS Rio, 08 dez. 2016. Disponível em: <https://feed.itsrio.org/nove-perguntas-sobre-o-direito-ao-esquecimento-dbacefdbbe5c>. Acesso em: 13 jul. 2018.

BRASIL. Lei n 12.965/14, de 23 de abril de 2014. Estabelece princípios, garantias, direitos e deveres para o uso da Internet no Brasil. Diário Oficial da União, Brasília, DF, 24 abr. 2014. Disponível em: <http://www.planalto.gov.br/ccivil_03/_ato2011-2014/2014/lei/112965.htm>. Acesso em: 11 jul. 2018 .

CASTELLS, Manuel. A sociedade em rede. São Paulo: Paz e Terra, 1999.

EUROPA. General Data Protection Regulation. (EU 2016/679). April 14, 2016. Disponível em: <https://www.eugdpr.org/>. Acesso em: 13 jul. 2018.

EUROPA. Tribunal de Justiça da União Europeia. Processo C-131/12. 13 maio 2014. Disponível em: <http://curia.europa.eu/juris/liste.jsf?num=C-131/12>. Acesso em: 30 maio 2017.

EUROPA. Tribunal de Justiça da União Europeia. Processo C-101/01. 06 nov. 2003. Disponível em: $<$ http://curia.europa.eu/juris/liste.jsf?language =pt\&num=C-101/01>. Acesso em: 12 jul. 2018.

EUROPA. Tribunal de Justiça da União Europeia. Processo C-73/07. 21 fev. 2009. Disponível em: <http://curia.europa.eu/juris/documents.jsf?num=C-73/07>. Acesso em: 12 jul. 2018.

GIL-LEIVA, Isidoro. A indexação na internet. Brazilian Journal of Information

Science, v. 1, n. 2, p. 47-68, jul./dez. 2007.

GOOGLE. Remoção de conteúdo do Google. Ajuda do Jurídico. Disponível em: <https://support. google.com/legal/troubleshooter/1114905 $\mathrm{hl}$ hl=pt-BR\#ts=1115655\%2C6034194 > . Acesso em: 11 jul. 2018a.

19 Um VPN, ou Virtual Private Network, é uma rede privada virtual que tem por objetivo estabelecer conexões seguras através de protocolos não seguros (SARLO, 2003). 
GOOGLE. Remoções da pesquisa em cumprimento da legislação europeia sobre privacidade. Transparency Report. Disponível em: <https://transparencyreport.google.com/eu-privacy/overview>. Acesso em: 12 jul. 2018b.

MARSHALL, Perry; RHODES, Mike; TODD, Bryan. Ultimate guide to Google AdWords. Entrepeneur Press, 2014.

MORGADO, Laerte Ferreira. O cenário internacional de proteção de dados pessoais. Necessitamos de um Código Brasileiro? Âmbito Jurídico. Disponível em <http://www.ambitojuridico.com.br/ site/index.php?.n_link=revista_artigos_leitura\&artigo_id=6336>. Acesso em: 24 jun. 2017.

PARENTONI, Leonardo Netto. O direito ao esquecimento (right to oblivion). In: DE LUCCA, Newton; SIMÃO FILHO, Adalberto; LIMA, Cíntia Rosa Pereira de (Coord.). Direito \& Internet Tomo I: Marco Civil da Internet (Lei no 12.965/2014). São Paulo: Quartier Latin, 2015.

RODRIGUES JÚNIOR, Otavio Luiz. Direito de apagar dados e a decisão do tribunal europeu no caso Google Espanha. 2014. Disponível em <http://www.conjur.com.br/2014-mai-21/direito-apagar-dados-decisao-tribunal-europeu-google-espanha > . Acesso em: 30 maio 2017.

SARLO, Lino da Silva. VPN: Aprenda a Construir Redes Privadas Virtuais em Plataformas Linux e Windows. São Paulo, Novatec, 2003.

SARLET, Ingo Wolfgang. Do caso Lebach ao caso Google vs. Agencia Espanhola de Proteção de Dados. 2015. Disponível em: <https://www.conjur.com.br/2015-jun-05/direitos-fundamentais-lebach-google-vs-agencia-espanhola-protecao-dados-mario-gonzalez>. Acesso em: 30 maio 2017.

UNIÃO EUROPEIA. Directiva 95/46/CE do Parlamento Europeu e do Conselho, de 24 de outubro de 1995. Relativa à protecção das pessoas singulares no que diz respeito ao tratamento de dados pessoais e à livre circulação desses dados. Jornal Oficial das Comunidades Europeias, 23 nov. 1995. Disponível em: <http://eur-lex.europa.eu/legal-content/PT/TXT/PDF/? uri=CELEX:31995L0046\&from=PT>. Acesso em: 30 maio 2017.

WACHOWICZ, Marcos. Cultura Digital e Marco Civil da Internet: contradições e impedimentos jurídicos no acesso à informação. In: LUCCA, Newton de; SIMÃO FILHO, Adalberto; LIMA, Cintia Rosa Ferreira de. Direito \& Internet. São Paulo: Editora Quartier Latin, 2015. p. 236.

Data da submissão: 03 de fevereiro de 2018 Avaliado em: 10 de julho de 2018 (AVALIADOR A) Aceito em: 11 de julho de 2018 
